\title{
Effect of Intermittent Endogenous Hyperglucagonemia on Glucose Homeostasis in Normal and Diabetic Man
}

\author{
Robert Rizza, Carlos Verdonk, John Miles, F. John Service, and John Gerich, \\ Diabetes and Metabolism Research Laboratory, Endocrine Research Unit, \\ Departments of Medicine and Physiology, Mayo Clinic and Medical School, \\ Rochester, Minnesota 55901
}

A B S T RACT Infusion of glucagon causes only a transient increase in glucose production in normal and diabetic man. To assess the effect of intermittent endogenous hyperglucagonemia that might more closely reflect physiologic conditions, arginine (10 g over $30 \mathrm{~min}$ ) was infused four times to 8 normal subjects and 13 insulin-dependent diabetic subjects ( 4 of whom were infused concomitantly with somatostatin to examine effects of arginine during prevention of hyperglucagonemia). Each arginine infusion was separated by $60 \mathrm{~min}$. Diabetic subjects were infused throughout the experiments with insulin at rates $(0.07-0.48 \mathrm{mU} / \mathrm{kg}$ per $\mathrm{min})$ that had normalized base-line plasma glucose and rates of glucose appearance (Ra) and disappearance (Rd). Basal plasma glucagon and arginine-induced hyperglucagonemia were similar in both groups; basal serum insulin in the diabetics $(16 \pm 1 \mu \mathrm{U} / \mathrm{ml}, P<0.05)$ exceeded those of the normal subjects $(10 \pm 1 \mu \mathrm{U} / \mathrm{ml}, P<0.05)$ but did not increase with arginine. Serum insulin in normal subjects increased $15-20 \mu \mathrm{U} / \mathrm{ml}$ with each arginine infusion. In both groups each arginine infusion increased plasma glucose and Ra. Increments of Ra in the diabetics exceeded those of normal subjects, $(P<0.02)$; Rd was similar in both groups. In normal subjects, plasma glucose returned to basal levels after each arginine infusion, whereas in the diabetics hyperglycemia persisted reaching $151 \pm 15 \mathrm{mg} / \mathrm{dl}$ after the last arginine infusion. When glucagon responses were prevented by somatostatin, arginine infusions did not alter plasma glucose or Ra.

Conclusions: Infusion of arginine acutely increases plasma glucose and glucose production in man solely by stimulating glucagon secretion; physiologic incre-

This work was presented in part at the 28th Annual Meeting of the American Diabetes Association, Boston, Mass. 11-13 June 1978.

Dr. Rizza was a recipient of a National Institutes of Health Research Fellowship Award, AM05827.

Received for publication 26 June 1978 and in revised form 29 January 1979. ments in plasma glucagon $(100-150 \mathrm{pg} / \mathrm{ml}$ ) can result in sustained hyperglycemia when pancreatic beta cell function is limited.

\section{INTRODUCTION}

Glucagon is a potent stimulator of hepatic glycogenolysis and gluconeogenesis (1). Nevertheless, its physiologic significance and role in diabetes mellitus has recently been questioned by observations that sustained hyperglucagonemia causes only a transient increase in glucose production in vivo $(2-5)$, and that prolonged exposure of the liver to hyperglucagonemia in vitro results in diminished ability of glucagon to stimulate glycogenolysis (6), to activate adenylate cyclase (7), and to bind to its plasma membrane receptors (8-10). However, because glucagon secretion varies throughout the day as a result of intermittent stimuli such as meals (11-14), exercise $(15,16)$, and stress $(17,18)$, the liver in vivo is usually exposed to fluctuating glucagon levels; thus, conclusions based upon the effects of sustained hyperglucagonemia may not necessarily reflect the actions of glucagon under physiologic conditions. The present studies were, therefore, undertaken to examine the effects on glucose homeostasis of intermittent hyperglucagonemia produced endogenously by administration of the glucagon secretagogue arginine in normal and diabetic man.

\section{METHODS}

Informed consent was obtained from 8 normal subjects $(2$ men, 6 women) $18-45 \mathrm{yr}$ of age (mean, $27 \mathrm{yr}$ ) with no family history of diabetes and also from 13 juvenile onset-type diabetic subjects ( 3 men, 10 women) 18-55 yr of age (mean, $29 \mathrm{yr}$ ) with documented histories of ketoacidosis. All subjects were in apparent good health at the time of the study and within $15 \%$ of their ideal body weight (Metropolitan Life Insurance Co. Tables, 1959).

All studies were begun between 6:00 and 7:00 a.m. with subjects in the postabsorptive state, having consumed weight maintenance diets containing 250-300 g carbohydrates for at least $3 \mathrm{~d}$. All subjects were admitted to a metabolic ward on 
the day before the study; the diabetic subjects were withdrawn from their long-acting insulin (neutral protamine Hagedorn or lente) treatment; initially they were managed for $24 \mathrm{~h}$ solely with multiple subcutaneous injections of regular insulin (5-10 $\mathrm{U}, 30 \mathrm{~min}$ before meals), and then by an overnight infusion of glucagon-free regular insulin (Eli Lilly \& Co., Indianapolis, Ind.). To examine the effects of arginine in the absence of its ability to stimulate glucagon secretion, four of the diabetic subjects were infused with somatostatin $(100 \mu \mathrm{g} / \mathrm{h}$, courtesy of Dr. Jean Rivier and Dr. Roger Guillemin, Salk Institute, San Diego, Calif.) and glucagon $(0.65 \mathrm{ng} / \mathrm{kg}$ per min, Eli Lilly \& Co.) beginning $8 \mathrm{~h}$ before the initial arginine infusion (vide infra). The somatostatin infusion was maintained constant throughout the study; the glucagon infusion rate was increased to $3 \mathrm{ng} / \mathrm{kg}$ per min from minute 330 (30 min after the last arginine infusion) to minute $360.4-6 \mathrm{~h}$ before study, the insulin infusion rate was adjusted to achieve stable normoglycemia as described (19) and, once established, this infusion rate $(0.07-0.48 \mathrm{mU} / \mathrm{kg}$ per $\mathrm{min})$ was maintained constant throughout the study. All hormones were made up on the morning of each study in $0.9 \% \mathrm{NaCl}$ containing $1 \mathrm{~g} / 100 \mathrm{ml}$ human serum albumin, (Cutter Laboratories, Inc., Berkeley, Calif.).

After insertion of three forearm intravenous catheters (No. 18 gauge angiocaths) at separate sites for blood sampling and administration of drugs, a primed ( $15 \mu \mathrm{Ci}$ bolus) continuous $(0.15 \mu \mathrm{Ci} / \mathrm{min})$ infusion of $\left[3^{3} \mathrm{H}\right]$ glucose $(100 \mu \mathrm{Ci} / \mu \mathrm{g}$ sp act, New England Nuclear, Boston, Mass., investigational new drug $12,755,100 \mu \mathrm{Ci} / 50 \mathrm{~cm}^{3}$ in $0.9 \% \mathrm{NaCl}$ ) was administered with a Harvard pump (Harvard Apparatus Co., Inc., Millis, Mass.); $2 \mathrm{~h}$ were allowed for attaining isotope equilibration. Both groups then received four separate $10 \mathrm{~g}$ arginine $(10 \mathrm{~g} /$ $100 \mathrm{ml}$, Cutter Laboratories, Inc.) infusions administered via Harvard pumps over $30 \mathrm{~min}$; each infusion was separated by $60 \mathrm{~min}$.

Blood samples were taken at 10- to 15-min intervals throughout the experimental period for determination of plasma glucose (11), glucagon (20), serum insulin (21) and, in the case of the diabetic subjects, "serum-free insulin" (22) henceforth referred to simply as insulin. Plasma $(1.6 \mathrm{ml})$ was added to cold $3 \mathrm{M}$ perchloric acid $(0.3 \mathrm{ml})$; duplicate aliquots of the resultant deproteinized plasma were evaporated to dryness under compressed air at $37^{\circ} \mathrm{C}$ to remove tritiated water. The residue was resuspended in $0.5 \mathrm{ml}$ distilled water and its radioactivity counted after addition of $10 \mathrm{ml}$ Aquasol (New England $\mathrm{Nu}$ clear). Quench was corrected for using external standard ratios. Plasma glucose specific activity was obtained by dividing the radioactivity by the plasma glucose concentration. Glucose appearance $(\mathrm{Ra})^{1}$ and disappearance (Rd) were determined by modifications (23) of the formula of Wall et al. (24) for nonsteady-state conditions. Glucose clearance (MCR) was calculated by dividing $\mathrm{Rd}$ by the simultaneous plasma glucose level. The validity of free insulin determinations (25), the formula for calculating $\operatorname{Ra}$ and $\operatorname{Rd}(26)$, and the use of $\left[3-{ }^{3} \mathrm{H}\right]-$ glucose as a nonrecycling tracer to estimate glucose turnover (27) have all been previously discussed in detail. Data in text and figures are given as mean \pm SEM. Differences within the same subject group were evaluated for statistical significance with two-tailed paired $t$ tests; elsewhere nonpaired $t$ tests were used.

\section{RESULTS}

Glucose, insulin, and glucagon responses to arginine infusions. In Fig. 1, the effects of the four arginine infusions on circulating glucose, insulin, and glucagon

\footnotetext{
${ }^{1}$ Abbreviations used in this paper: MCR, glucose clearance;
} $\mathrm{Ra}$, glucose appearance; Rd, glucose disappearance. levels in normal and diabetic subjects are shown. Baseline plasma glucose and glucagon levels were similar in both groups; serum insulin levels in the diabetics $(16 \pm 1 \mu \mathrm{U} / \mathrm{ml})$ were significantly greater than those of the normal subjects $(10 \pm 1 \mu \mathrm{U} / \mathrm{ml}, P<0.05)$. In both groups, plasma glucose levels increased with each arginine infusion; however, successive arginine infusions produced smaller increments. In normal subjects, plasma glucose increased an average of 8-16 mg/dl during the infusions and returned to preinfusion levels within 20-40 min after termination of the arginine. In the diabetic subjects, plasma glucose increased to significantly greater levels than those observed in the normal subjects with each arginine infusion $(P<0.005)$ and did not return to base-line values between infusions although levels decreased before the subsequent infusion. This response pattern in the diabetic group resulted in sustained hyperglycemia throughout the study such that at the end of the fourth arginine infusion, plasma glucose averaged $151 \pm 15 \mathrm{mg} / \mathrm{dl}$ compared to $91 \pm 2 \mathrm{mg} / \mathrm{dl}$ in the normal subjects $(P<0.005)$.

These different glycemic responses occurred despite virtually identical plasma glucagon responses to the arginine infusions in both groups throughout the study. Serum insulin concentrations of the normal subjects paralleled plasma glucose levels, rising 15-20 $\mu \mathrm{U} / \mathrm{ml}$ with each arginine infusion. In contrast, serum insulin levels of the diabetic subjects did not change during the arginine infusions. Although these concentrations of insulin were significantly greater than those observed in the normal subjects during the base-line period and between arginine infusions ( $16 \pm 1$ vs. $10 \pm 1 \mu \mathrm{U} / \mathrm{mg}, P$ $<0.05$ ), they were significantly less than those of the

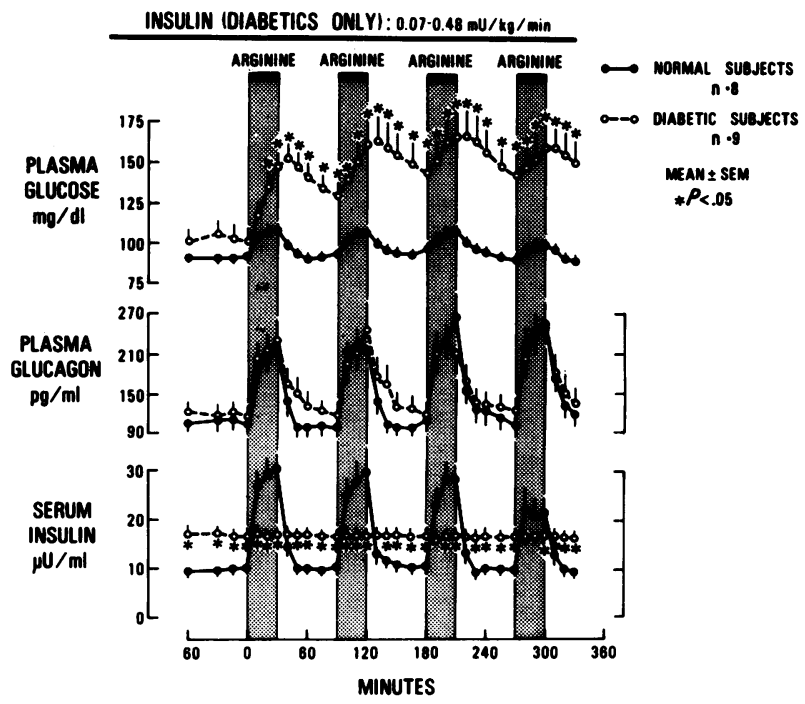

Figure 1 Blood glucose, glucagon, and insulin levels during intermittent infusion of arginine in normal subjects and in insulin-dependent diabetic subjects. 
normal subjects during the arginine infusions (25-30 vs. $16 \mu \mathrm{U} / \mathrm{ml}, P<0.05)$.

$R a, R d$, and MCR rates during arginine infusions. In Fig. 2, the effects of the four arginine infusions on $\mathrm{Ra}, \mathrm{Rd}$, and MCR in normal and diabetic subjects are shown. In both groups, base-line values for $\mathrm{Ra}, \mathrm{Rd}$, and MCR were similar. Ra increased with each arginine infusion in both groups; responses after the third and fourth infusions were less than that after the initial infusion in each group (areas under the curve, $P$ $<0.05$ ). During all infusions, the diabetic subjects had significantly greater increases in Ra than did the normal subjects (areas under the curve, $P<0.02$ ). Rd increased with each arginine infusion and was not significantly different in the two groups throughout the study. In the normal subjects, MCR increased with each arginine infusion, whereas in the diabetic group it decreased $\cong 20 \%$ to values significantly less than those in the normal subjects, $(P<0.05)$.

Effect of somatostatin on plasma glucose and glucagon concentrations and rates of Ra and Rd during arginine infusions in diabetic subjects. In Fig. 3 the circulating glucose, glucagon, and insulin concentrations and the rates of Ra and Rd observed during the arginine infusions in the diabetics studied above are compared to those in four additional diabetic subjects infused with somatostatin and glucagon. Somatostatin was infused to examine the effects of arginine on plasma glu-

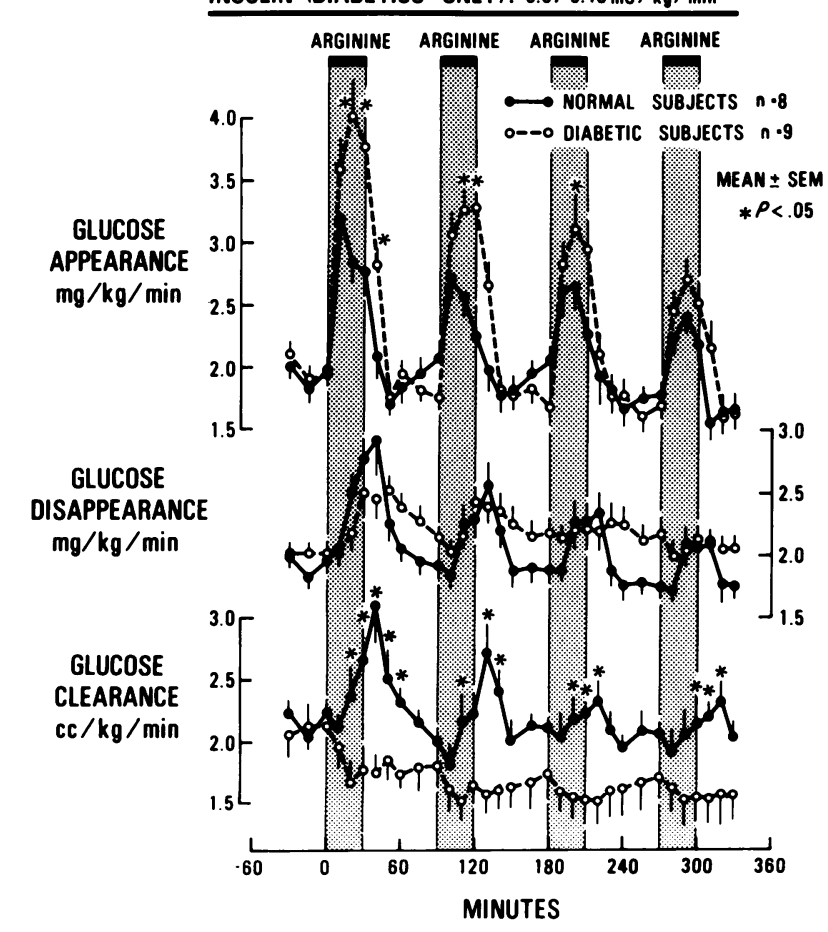

Figure 2 Ra, Rd, and MCR during intermittent infusion of arginine in normal subjects and in insulin-dependent diabetic subjects.

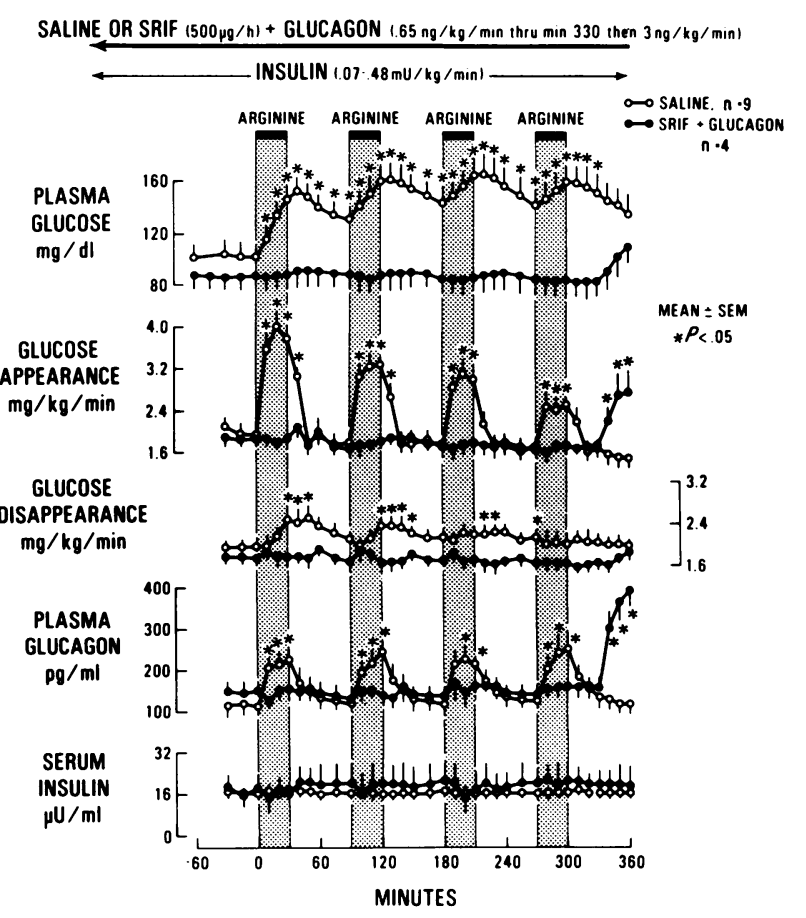

Figure 3 Effect of somatostatin on blood glucose, glucagon, and insulin levels and rates of Ra and Rd during intermittent infusion of arginine in insulin-dependent diabetic subjects.

cose and Ra under conditions when stimulation of glucagon secretion by arginine would be prevented; glucagon was infused concomitantly to maintain basal plasma glucagon levels during suppression of endogenous glucagon secretion by somatostatin. In both groups of subjects, basal values for plasma Ra, Rd, plasma glucagon, and serum insulin were comparable and not significantly different. Plasma glucagon and serum insulin in the somatostatin-infused subjects remained at basal levels throughout the study. In contrast to the increases in plasma glucose and Ra that occurred with each arginine infusion in the diabetic subjects not infused with somatostatin, plasma glucose and Ra did not vary significantly from base-line values after administration of arginine in the diabetic subjects infused with somatostatin plus glucagon. However, then the glucagon infusion rate was increased from $0.65 \mathrm{ng} / \mathrm{kg}$ per min to $3 \mathrm{ng} / \mathrm{kg}$ per min in these subjects, plasma glucose and Ra promptly increased.

\section{DISCUSSION}

The physiologic significance of glucagon and its role in diabetes mellitus has recently been questioned by observations that sustained hyperglucagonemia produced by infusion of glucagon does not result in a sustained increase in plasma glucose or glucose production in man (3-5). The present studies were undertaken to determine the effects of intermittent endogenous hyperglucagonemia on glucose homeostasis in man because 
this might reflect physiologic conditions more closely than sustained infusions of exogenous glucagon. An additional purpose of the present studies was to determine the effect of intermittent hyperglucagonemia on glucose homeostasis in diabetic subjects infused with sufficient insulin to maintain normal basal circulating glucose levels and glucose turnover rates because it had been suggested that glucagon would not cause deterioration in blood glucose regulation in the absence of severe insulin deficiency (28). Infusion of arginine, a secretagogue of both glucagon and insulin, was chosen to promote endogenous hyperglucagonemia; this amino acid would not be expected to acutely alter glucose metabolism under the present experimental conditions other than by altering insulin and glucagon secretion because it has been demonstrated that during infusion of ${ }^{14} \mathrm{C}$ arginine in man, no arginine is incorporated into plasma glucose before $30-50 \mathrm{~min}(29)$ and because it has also been shown that infusion of arginine in pancreatectomized dogs for 90 min does not alter glucose turnover when changes in plasma insulin and glucagon were prevented (30). This premise was substantiated in the current study inasmuch as infusion of arginine did not cause an increase of either plasma glucose or $\mathrm{Ra}$ in diabetic subjects when glucagon responses to arginine were prevented by a concomitant infusion of somatostatin during maintenance of constant basal levels of circulating glucagon and insulin by means of exogenous infusion of these hormones. The fact that both plasma glucose and Ra increased appropriately when the glucagon infusion rate was increased, indicates that the liver was still responsive to glucagon under these conditions.

In both the normal and diabetic subjects, each episode of arginine-induced hyperglucagonemia during the 5.5-h study period increased plasma glucose levels and $\mathrm{Ra}$ rates. In should be noted, however, that in both groups of subjects, increments in plasma glucose and $\mathrm{Ra}$ were less during the third and fourth arginine infusions than during the initial infusion despite comparable insulin and glucagon responses thus indicating that, as with continuous exogenous hyperglucagonemia $(3,4)$, hepatic downregulation also occurs with intermittent endogenous hyperglucagonemia. A similar deccremental response of $\mathrm{Ra}$ has been observed in dogs during repetitive increases in infusion rates of exogenous glucagon during concomitant infusion of somatostatin (31).

In the normal subjects, plasma glucose increased moderately during arginine infusions and returned to base-line levels between the infusions. In the diabetic subjects, plasma glucose increased to a greater extent than in normal subjects and did not return to base-line levels between arginine infusions so that in the diabetic subjects intermittent hyperglucagonemia resulted in sustained fasting hyperglycemia averaging $>150 \mathrm{mg} / \mathrm{dl}$ at the end of the last arginine infusion. The difference in glycemic responses of the normal and diabetic subjects was primarily the result of greater increases in Ra that occurred with each arginine infusion in the diabetics because Rd rates were similar in the normal and diabetic subjects. However, it is evident from the MCR rates that the diabetics disposed of glucose less effectively than the normal subjects.

The greater increments in Ra observed in the diabetics occurred despite virtually identical glucagon responses to arginine in the normal and diabetic groups. Whether this was a result of increased sensitivity to glucagon in the diabetics, a possibility suggested by recent studies demonstrating enhanced glucagon binding to its receptors in livers from streptozotocin-diabetic rats (31), or, more likely, because of a lack of insulin secretion in response to arginine in the diabetic subjects (or a combination of both factors) cannot be answered from the present studies. It should be pointed out that in the present study the diabetic subjects were not severely insulin deficient: they had been infused throughout the experiment with insulin at a rate that had maintained their base-line peripheral venous insulin levels one and one-half times greater than those of the normal subjects, and which rendered their baseline plasma glucose levels and glucose turnover rates indistinguishable from those of the normal subjects. Previously, it has been suggested that glucagon would not have an appreciable hyperglycemic effect except under circumstances of severe insulin deficiency (32). However, it has been recently reported that continuous infusion of exogenous glucagon, producing increments in plasma glucagon levels of $200-250 \mathrm{pg} / \mathrm{ml}$, caused deterioration of diabetic control despite concomitant constant infusion of insulin (33). In the present study, four increments of plasma glucagon $(100-150 \mathrm{pg} / \mathrm{ml})$ were produced during a 5.5 -h period; although plasma glucagon may increase abruptly during various kinds of stress (15-18), whether such changes in plasma glucagon would occur as frequently under conditions of daily life is unclear. However, increments in plasma glucagon of similar magnitude to those produced in the present study have been reported to occur postprandially in normal (12) and diabetic (11) man. Thus, an individual having breakfast, a midmorning snack, and lunch would have a minimum of three episodes of hyperglucagonemia over a $6-\mathrm{h}$ period. The present studies indicate that such hyperglucagonemia can cause sustained hyperglycemia in man when pancreatic beta cell function is limited.

\section{ACKNOWLEDGMENTS}

The excellent assistance of K. Greene, B. Brick, J. King, R. Westland, W. Blanchard, the Clinical Study Unit nursing staff, and J. Hatteberg is gratefully acknowledged.

Supported in part by grants (AM20411, AM20837, and AM- 
05827) from the U. S. Public Health Service and the Mayo Foundation.

\section{REFERENCES}

1. Park, C., and J. Exton. 1972. Glucagon and the metabolism of glucose. In Glucagon, Molecular Physiology and Therapeutic Implications. P. Lefebvre and R. Unger, editors. Pergammon Press, Inc., New York. 17-108.

2. Cherrington, A., and M. Vranic. 1974. Effect of interaction of insulin and glucagon on glucose turnover and FFA concentration in normal and depancreatized dogs. Metab. Clin. Exp. 27: 729-744.

3. Felig, P., J. Wahren, and R. Hendler. 1976. Influence of physiologic hyperglucagonemia on basal and insulin-inhibited splanchnic glucose output in normal man.J. Clin. Invest. 58: 761-765.

4. Bomboy, J., S. Lewis, W. Lacy, B. Sinclair-Smith, and J. Liljenquist. 1977. Transient stimulatory effect of sustained hyperglucagonemia on splanchnic glucose production in normal and diabetic man. Diabetes. 26: 177-184.

5. Sherwin, R., W. Tamborlane, R. Hendler, L. Sacca, R. DeFronzo, and P. Felig. 1977. Influence of glucagon replacement on the hyperglycemic and hyperketonemic response to prolonged somatostatin infusion in normal man. J. Clin. Endocrinol. Metab. 45: 1104-1107.

6. Plas, C., and J. Nunez. 1975. Glycogenolytic response to glucagon of culture fetal hepatocytes: refractoriness following prior exposure to glucagon. J. Biol. Chem. 250: 5304-5311.

7. DeRubertis, F., and P. Craven. 1976. Reduced sensitivity of the hepatic adenylate cyclase-cylcic AMP system to glucagon during sustained hormonal stimulation. J. Clin. Invest. 57: 435-443.

8. Srikant, C., D. Freeman, K. McCorkle, and R. Unger. 1977. Binding and biologic activity of glucagon in liver cell membranes of chronically hyperglucagonemic rats. $J$. Biol. Chem. 252: 7434-7436.

9. Bhathena, S., N. Voyles, S. Smith, and L. Recant. 1978. Decreased glucagon receptors in diabetic rat hepatocytes. Evidence for regulation of glucagon receptors by hyperglucagonemia. J. Clin. Invest. 61: 1488-1497.

10. Soman, V., and P. Felig. 1978. Regulation of the glucagon receptor by physiologic hyperglucagonemia. Nature (Lond.). 272: 829-831.

11. Gerich, J., T. Schultz, S. Lewis, and J. Karam. 1977. Clinical evaluation of somatostatin as a potential adjunct to insulin in the management of diabetes mellitus. Diabetologia. 13: 537-544.

12. Dencker, H., P. Hedner, J. Holst, and K. Tranberg. 1975. Pancreatic glucagon response to a normal meal. Scand.J. Gastroenterol. 10: 471-474.

13. Wahren, J., P. Felig, and L. Hagenfeldt. 1976. Effect of protein ingestion on splanchnic and leg metabolism in normal man and in patients with diabetes mellitus. J. Clin. Invest. 57: 987-999.

14. Raskin, P., and R. Unger. 1978. Effect of insulin therapy on the profiles of plasma immunoreactive glucagon in juvenile-type and adult-type diabetics. Diabetes. 27: 411-419.

15. Galbo, H., J. Holst, and N. Christensen. 1975. Glucagon and plasma catecholamine responses to graded and prolonged exercise in man. J. Appl. Physiol. 38: 70-76.
16. Wahren, J., L. Hagenfeldt, and P. Felig. 1975. Splanchnic and leg exchanges of glucose, amino acids, and free fatty acids during exercise in diabetes mellitus. J. Clin. Invest. 55: 1303-1314.

17. Gerich, J., and M. Lorenzi. 1978. The role of the autonomic nervous system and somatostatin in the control of insulin and glucagon secretion. In Frontiers in Neuroendocrinology. W. Ganong and L. Martini, editors. Raven Press, New York. 5: 265-288.

18. Unger, R., and L. Orci. 1976. Physiology and pathophysiology of glucagon. Physiol. Rev. 56: 778-834.

19. Gerich, J., M. Lorenzi, D. Bier, V. Schneider, E. Tsalikian, J. Karam, and P. Forsham. 1975. Prevention of human diabetic ketoacidosis by somatostatin: evidence for an essential role of glucagon. N. Engl. J. Med. 292: 985-989.

20. Faloona, G., and R. Unger. 1974. Glucagon. In Methods of Hormone Radioimmunoassay. B. Jaffee and $\mathrm{H}$. Behrman, editors. Academic Press, Inc., New York. 317-330.

21. Herbert, V., K. Lau, C. Gottlieb, and S. Bleicher. 1965. Coated charcoal immunoassay of insulin. J. Clin. Endocrinol. Metab. 25: 1375-1384.

22. Nakagawa, S., H. Nakayama, T. Sasaki, K. Yoshima, Y. Yu, K. Shinozaki, S. Aoki, and K. Mashimo. 1973. A simple method for the determination of serum free insulin levels in insulin-treated patients. Diabetes. 22: 590-600.

23. Cowan, J., and G. Hentenyi. 1971. Glucoregulatory responses in normal and diabetic dogs recorded by a new tracer method. Metab. Clin. Exp. 20: 360-372.

24. Wall, J., R. Steele, R. DeBodo, and N. Altszuler. 1957. Effect of insulin on utilization and production of circulating glucose. Am. J. Physiol. 189: 43-50.

25. Kuzuya, H., P. Blix, D. Horwitz, D. Steiner, and A. Rubenstein. 1977. Determination of free and total insulin and C-peptide in insulin-treated diabetics. Diabetes. 26: 22-29.

26. Radzuik, J., K. Norwich, and M. Vranic. 1974. Measurement and validation of nonsteady state turnover rates with applications to the insulin and glucose system. Fed. Proc. 33: 1855-1864.

27. Altszuler, N., A. Barkai, C. Bjerknes, B. Gottlieb, and R. Stelle. 1975. Glucose turnover values in the dog obtained with various species of labeled glucose. Am. J. Physiol. 229: $1662-1667$.

28. Sherwin, R., M. Fisher, R. Hendler, and P. Felig. 1976. Hyperglucagonemia and blood glucose regulation in normal, obese and diabetic subjects. N. Engl. J. Med. 294: 455-461.

29. Felig, P., and E. Marliss. 1972. The glycemic response to arginine in man. Diabetes. 21: $308-310$.

30. Cherrington, A., R. Kawamori, S. Pek, and M. Vranic. 1974. Arginine infusion in dog model for the roles of insulin and glucagon in regulating glucose turnover and free fatty acid levels. Diabetes. 23: 805-815.

31. Cherrington, A., W. Lacy, and J. Chiasson. 1978. Effect of glucagon on glucose production during insulin deficiency in the dog. J. Clin. Invest. 62: 664-677.

32. Soman, V., and P. Felig. 1978. Glucagon binding and adenylate cyclase activity in liver membranes from untreated and insulin-treated diabetic rats. J. Clin. Invest. 61: 552-560.

33. Raskin, P., and R. Unger. 1978. Hyperglucagonemia and its suppression: Importance in the metabolic control of diabetes. N. Engl. J. Med. 299: 433-436. 